\title{
Design of a Green Automated Wireless System for Optimal Irrigation
}

\author{
Andrews A. Okine \\ School of Communication \& Information Engineering, Chongqing University of Posts and Telecommunications, \\ Chongqing, PR China \\ E-mail: andyokine101@gmail.com \\ Michael O. Appiah \\ College of Animal Science \& Technology, Jilin Agricultural University, PR China \\ E-mail: moa4short@outlook.com \\ Ibrar Ahmad \\ School of Agricultural Equipment Engineering, Jiangsu University, PR China \\ E-mail: Ibrar.ahmad@yahoo.com \\ Bismark Asante-Badu \\ College of Resources \& Environmental Science, Jilin Agricultural University, PR China \\ E-mail: allosbismac@gmail.com \\ Benjamin B. Uzoejinwa \\ Department of Agricultural \& Bioresources Engineering, University of Nigeria, Nigeria \\ E-mail: benjamin.uzoejinwa@unn.edu.ng
}

Received: 05 February 2020; Accepted: 30 March 2020; Published: 08 June 2020

\begin{abstract}
Towards sustainable agriculture, the management of scarce water resources has become more crucial. In this article, we proffer a green automated wireless system (GAWS) aimed at maximizing and efficiently utilizing water resources for irrigation. The proposed irrigation system is a green technology which will be powered exclusively by solar energy. In its operation, it uses solar-powered wireless sensors for obtaining and transmitting information about soil moisture content of different segments on a given farm. The GAWS will ensure that irrigation is done only when necessary via a solar-powered irrigation control centre. For optimal irrigation, the automated intelligent control centre is designed to trigger solar-powered groundwater pumps wirelessly to execute necessary irrigation for a particular portion of the farm and fall back on an external irrigation system if that proves insufficient. It is envisaged that the proposed irrigation system will improve total crop yields by maximizing the utility of scarce water resources from both internal and external irrigation sources. It will also minimize the cost of time and labour involved in irrigation management, harness renewable energy and be environmentally friendly.
\end{abstract}

Index Terms-Crop water requirement, green energy, groundwater, irrigation systems, wireless sensor networks.

\section{INTRODUCTION}

Agriculture assumes an essential role in the global economy and, by and large, in the survival of countries, since it gives the fundamental subsistence to the whole populace of a nation while in the meantime it connects with several different industries. Particularly in rural regions, occupants rely upon agriculture as it is basic for their nourishment as well as comprises the base of all trade. Agriculture is likewise the most prevalent activity in developing countries for sustenance and other crucial things utilized by living organisms to sustain and improve their life. Agriculture utilizes $85 \%$ of accessible freshwater resources worldwide for cultivating crops by utilizing traditional irrigation water system techniques and it also increases the demand for water resources in everyday life as the populace grows [1]. Additionally, the regularly expanding total populace demands larger amount of food which in this manner surmises a wellmanaged and cost-effective agriculture. All throughout the world, irrigation is one of the primary water consumers and as indicated by ongoing reports, Agriculture irrigation represents $50-60 \%$ of freshwater usage from sources in the indigenous habitat and up to over $90 \%$ in some developing nations [2]. Without 
irrigation, crops could never have been grown in the deserts of California and Israel. Irrigation is additionally a fundamental part of crop production in numerous territories of the world. In cotton for instance, ongoing examinations have uncovered that proper timing of irrigation is a significant production factor and that delaying irrigation can result in losses of between USD 62/ha and USD 300/ha [3].

Irrigation has also been around for long as human have been cultivating plants. Despite the fact that the traditional method of pouring water on fields is as yet a common irrigation system strategy, other progressively effective and mechanized techniques are likewise utilized. One of the more prevalent mechanized techniques is the centre-pivot irrigation system [4], which utilizes moving spray guns or dripping faucet heads on wheeled tubes and that rotate around a focal source of water. Aside these, there are additionally a lot more irrigation techniques that farmers use today. Since there is dependably a need to discover increasingly proficient approaches to utilize water for irrigation, producers need to discover progressively compelling and effective utilization of water resources while keeping up high crop yields. The drip irrigation system also known as micro irrigation is an example of an irrigation technique that optimizes the utilization of water resources for improving crop yield and which likewise supplies water either directly to the root zone or soil surface through pressurized pipes, valves and drippers to make water drip gradually [5]. Drip irrigation system spares about $40-80 \%$ of water contrasted with traditional flood irrigation system technique which discharges water until the whole field is covered. However, the crop does not require that much measure of water amid its whole development period (i.e.) it requires just $50 \%$ and $25 \%$ of water in mid and early stages of cultivation compared with the completely developed stage. While the producers need to apply water to meet the needs of the crop, they should understand that with the traditional system of irrigation, yields and returns from the irrigated farm plot will be diminished when contrasted with a fully irrigated mechanized farm plot. Furthermore, to appropriately manage water for the best crop returns, producers must have a comprehension of how crops react to water, how crop rotation can upgrade irrigation management, and how changes in agronomic practices can impact the need for water. Water stress amid critical occasions may result in low yields and harvests, for example, corn, respond with more yields for every last bit of water that it expends when compared with different crops, like the winter wheat and soybeans. Notwithstanding, crops, for example, corn require more water for improvement or upkeep before any yield is delivered. Corn requires around $10 \mathrm{in}$. of water to produce the first increment of yield when compared with 4.5 and $7.5 \mathrm{in}$. for wheat and soybeans respectively [6].

Given the expanding worldwide deficiency of water brought about by a blend of a changing atmosphere and pressure as a result of extreme demand of agricultural products, it is of essential significance and need to develop an irrigation system control technique that permit the minimization of water wastage while keeping related expenses at an affordable level. Effective water management plays a significant role in irrigated agricultural cropping systems. Numerous territories of agricultural fields are successfully over or under-irrigated because of spatial variability in water penetration and spillover of rainfall and irrigation, crop water use and irrigation depth. Under-irrigated territories are liable to water stress, bringing about reduction in production, while over-irrigated zones experience plant disease and nutrient leaching. A wireless sensor-based irrigation control system is a potential solution to optimize water management by remotely accessing in-field soil water conditions and site-specifically controlling irrigation sprinklers. Moreover, with the improvement of sensor innovation and network-based information technology, wireless sensor network (WSN) likewise assumes a noteworthy role in health care applications, military applications, intelligent home monitoring alongside precision agriculture in a greater extent [7-9]. Current sensor-based technology advertised as wireless are very costly on the grounds that they require conventional radio transmitters and as a rule require a government permit for utilization of the radio frequency (RF), and moreso requires broad cabling if numerous sensors are utilized. These products for the most part have high-energy prerequisites and furthermore need regular upkeep amid the growing season. In this way it is of essential significance to design a new irrigation control wireless system that permit the minimization of water wastage while keeping related expenses at a moderate level by exploiting a simple alternative source of energy for its whole irrigation activity.

In an agricultural area, several farms usually rely on finite sources of water for irrigation particularly during the dry seasons. Irrigation water can be obtained from springs, wells, streams, lakes, reservoirs and so on. Some of these sources are used simultaneously for other agricultural activities such as fishing and livestock farming. Besides, washing, bathing, drinking and cooking are typical domestic activities that consume water whose source can be traced to that of irrigation water. Since water is increasingly becoming scarce, the efficient utilization of water has become imperative. Proper irrigation management is one way of ensuring efficient usage of water resource. Over-irrigation of farm lands is a sheer waste of water resources hence, irrigation should be carried out in a way that just satisfies crop water needs. Besides, water requirements vary depending on a crop and season. Therefore, modern irrigation systems should be designed in a way that enables them to adapt to changing conditions. Traditional irrigation practices result in loss of productive hours, high cost of human labour and high cost of utilities. On the other hand, mechanized irrigation relying on fossil fuels is not environmentally friendly due to high $\mathrm{CO}_{2}$ emissions [10].

In this research article, we proposed a green mechanized irrigation wireless system that depends exclusively on green energy for its entire operation. This green automated framework has a wireless architecture 
that automatically recognizes the need for irrigation and can likewise exploit an alternative source of water and thus automatically execute the irrigation process. Our research will predominantly concentrate on solarpowered wireless soil moisture sensors that initially obtains and transmits information about the soil moisture content and a solar-powered groundwater pump that likewise extracts water from the ground. These will all be interconnected to a solar powered wireless control center that controls the whole irrigation process. This green mechanized wireless system developed will likewise provide proficient utilization of scarce water available bringing about higher crop yields and there will also be productive time savings, reduction in utility bills, decrease in labor cost and will likewise be environmentally friendly in light of the fact that a welldesigned irrigation system is a basic prerequisite for a productive and environmental friendly irrigation [11].

\section{RELATED WORKS}

During the last few decades, an eminent shrinkage in the available water resources is acknowledged while, on the other hand, escalating population growth, industrialization, climatic variability and petition of irrigation water is demanding efficient and sustainable utilization of water particularly in agriculture sector. Bearing in mind the above-mentioned issues, immense exploration has been accomplished by researchers globally but here specific and contemporary literature review is discussed related to automated wireless system for efficient irrigation.

The origin of autonomous irrigation system was acknowledged in 1930s [12] and the submission of sensors for detection of soil moisture was initiated in 1950s [13], and right now it is a dynamic perception in irrigation subdivision of agriculture sector of the world. It was observed that during the preceding decade, generally four types of techniques (SWC [14], SWT [15], canopy temperature [16, 17] and combined SWC and metrological data [18]) were applied to estimate the crop water requirements as input parameter of automatic irrigation system. With the improvement in wireless technology and by considering the detachment limitations associated with irrigation system, the application of wireless sensor for the purpose of monitoring and control was premeditated by researchers [19]. An intra-field wireless solution in the direction of automatic irrigation system was developed by [20] using ZigBee technology. The overall system consisted of the following fundamentals; wireless sensor node which was responsible for getting inputs from weather and transform it to portable controller, a portable controller was accountable to analyze the input data and released the instruction for actuator nodes and actuator nodes received the control instructions from controller and in authority to supervise the electromagnetic valves and pump. An automatic drip irrigation technique based on ZigBee wireless sensor system was developed and fuzzy logic control strategy was adopted in this piece of exploration. In the improvement of greenhouse facility, a Bluetooth base integrated control approach was practically applied to automatically irrigate the crops and findings of this research revealed that it can save $90 \%$ electricity in comparison with time control method [21]. After the successful application of wireless sensors network for efficient irrigation it is observed that the existing technology can be applied effectively in greenhouse but not suitable for remote areas. In order to solve this issue a solar operated wireless sensors base monitoring system for soil moisture consents at different depths was developed and tested successfully [22].

Authors in [23] presented a complete irrigation solution for farmers in his exploration based on WSN and this cost-effective automated irrigation system framework utilized low-cost sensor nodes, which gave a diminished power utilization and which additionally decreased the water wastage. The utilization of wireless sensor network innovation to advance irrigation in agriculture is of advantage to both the farmers and the environment and given the progress in the field of WSN just as in the scaling down of such sensor systems, new patterns have risen in the field of precision agriculture [24, 25]. Reviews of wireless sensor innovations and applications in agriculture and food industry have been given by [26] and [27]. Additionally these sensor-based irrigation system frameworks have been considered for many applications [28-32]. For instance, Stone et al. [28] presented a computer-based checking system for constant estimations of soil water potential while Zazueta and Smajstrla [30] additionally compared indirect estimates with direct estimation of soil moisture. Furthermore, Meron et al. [31] used a control framework for apple tree irrigation management utilizing tensiometers and Testezlaf et al. [32] also utilized an automated irrigation ontrol framework for the management of greenhouse container plants.

Due to the crucial role soil water plays in the growth and development of crops, water scarcity has become a major concern in the quest for sustainable agriculture. Although irrigation systems have been setup to help resolve the challenge of water scarcity and thus achieve all year round farming, most of these systems are labour intensive and time consuming [33, 34]. Also, many irrigation systems rely on fossil fuels which are not environmental friendly [35], at a time when global warming is a major issue. Meanwhile, the harnessing of renewable energy, for example solar energy, for irrigation has not received the needed attention. In order to cope with the unfavourable increased severity of water scarcity, modern irrigation systems have had to depend on unorthodox sources of water such as groundwater [36]. Thus, future irrigation systems will definitely have to rely on a multiplcity of water sources. This, therefore, calls for the design of new irrigation systems that can manage the scarce water from these sources efficiently so that irrigation water can be made available to as many farms as possible in an agricultual region. 


\section{IRRIGATION WATER REQUIREMENT}

In order to design an optimal irrigation system, it is necessary to understand the irrigation water requirements (IWR) of the various crops to be served. To this end, we determine the IWR based on the soil water balance on a particular day $j$ for a certain growing crop $i$ expressed mathematically as [43]:

$$
D_{i j}=D_{i(j-1)}-E T c r_{i j}+P_{j}+I D_{i j}-D P_{i j}+D_{R i j}
$$

where $D$ is the soil water content (expressed in terms of water depth, mm), ID is the irrigation depth, ETcr is the real crop evapotranspiration, $P$ is the precipitation, $D P$ is the deep percolation, and $D_{R}$ is the soil water content at the additional depth explored by the crop roots in its daily growth. The real crop evapotranspiration ETcr can be estimated, based on the crop coefficient $K_{C}$ and reference crop evapotranspiration $E T_{o}$, as $E T c r=E T_{o} * K_{C}$ [44]. By rearranging equation (1), the irrigation water requirement $I W R$ can be obtained as

$$
I W R=D_{i j}-\left(D_{i(j-1)}-E T c r_{i j}+P_{j}-D P_{i j}-D_{R i j}\right)
$$

Precipitation and evapotranspiration are the major factors that affect irrigation water requirement [45]. Furthermore, if we assume that $D_{i j} \approx D_{i(j-1)}$ then equation (3) can be approximated by

$$
I W R=E T c r_{i j}-P_{j}
$$

ETcr and $P$ are mainly influenced by the prevailing weather conditions and will change based on the pattern. Thus, the irrigation water requirement will also change from time to time. Also, $K_{C}$ is largely determined by the specific crop characteristics, which implies that irrigation water requirement also varies according to the type of crop. In order to design a water-efficient irrigation system, we must consider the specific requirements of crops. Such an irrigation system should carry out irrigation when necessary and only where it is needed.

\section{THE Proposed IRRIGATION SySTEM}

An irrigation system that relies on solar energy for its entire operation is proposed in this section. The proposed green automated wireless system (GAWS) automatically detects the need for irrigation, exploits alternative sources of water and automatically irrigates the required area. The GAWS is made up of four main components. These are solar-powered wireless sensor units (WSUs), solarpowered wireless control center (WCC), solar-powered groundwater pumps [37, 38] and solar-powered wirelessenabled irrigation control valves [39, 40]. Basically, the solar-powered WSUs obtain and transmit information about soil moisture content as depicted in Fig. 1. The solar-powered WCC controls the irrigation process in terms of the area to be irrigated, the source and amount of water to be applied. The WCC activates an irrigation control valve whenever it wants to water an area in which the valve is located. Solar-powered groundwater pumps are used to extract water from the ground. These pumps are employed in an alternate manner, based on the quantity of water required. The deployment of the GAWS on a given farm is illustrated schematically in Fig. 2. The figure shows the various WSUs placed on different segments of a farm. Within each segment, the WSUs are positioned at distant locations apart from one another to increase the timeliness of detecting water deficiency and relaying the information to the WCC using radio signals.

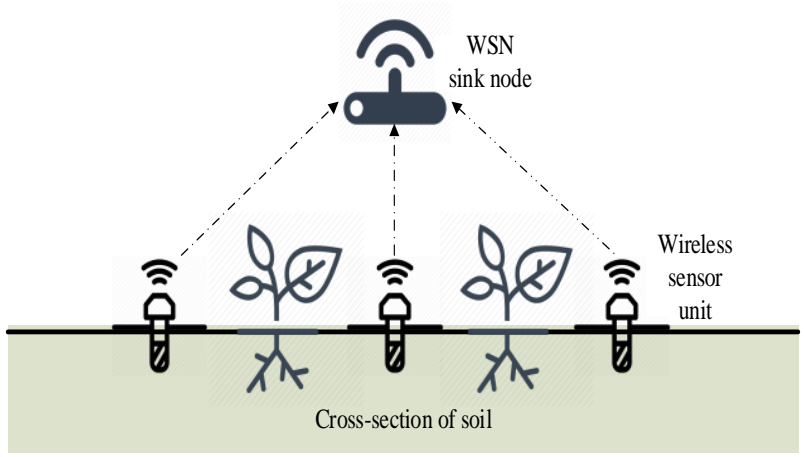

Fig.1. The application of WSUs for soil moisture detection and transmission

\section{A. Wireless Sensor Units (WSUs)}

The WSUs consist of RF transmitters, soil moisture sensors, a microcontroller, rechargeable batteries and a photovoltaic cell [41]. They are deployed to form a distributed sensor network. Soil moisture plays an important role in plant life. Plants grow by feeding on nutrients in the soil solution. In addition, moisture is vital for controlling plant temperature during the transpiration process. Achieving a healthy balance of water and moisture in the soil is crucial for producing high quality plants. Plants that are not watered enough suffer from nutrient deprivation, growth retardation, and wilt. In contrast, plants that are over-irrigated are more prone to disease and less resistant to drought conditions in subsequent life cycles. Besides, excessive soil moisture levels can cause plants to suffocate and die. To prevent these events from happening, soil moisture sensors as illustrated in Fig. 1 are used for measuring the volumetric water content (VWC) in the soil to make appropriate irrigation decisions. Volumetric soil water content is the volume of water per unit volume of soil. The WSU are linked together to form a wireless sensor network (WSN) which is connected to the irrigation control valves. The soil moisture sensors employ probes to detect variations in soil moisture content. The probes are inserted into the ground and the water content of the soil is determined by analyzing its effect on the dielectric constant measured by the capacitance between the two electrodes deposited in the soil. An electromagnetic field is established when the 
positive and earth electrodes are rapidly charged and discharged. The varying charging time $(t)$ is based on the capacitance $(C)$ of the soil which is given by the following equation:

$$
t=R C \operatorname{In}\left[\frac{V-V_{f}}{V_{i}-V_{f}}\right]
$$

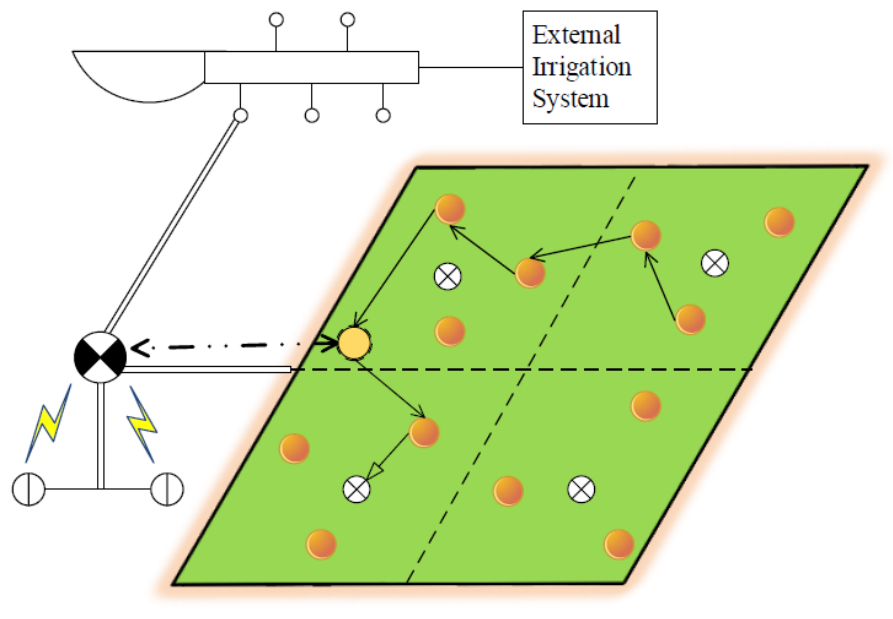

where $V$ is voltage at time $t, R$ is the series resistance, $V_{f}$ is the applied voltage and $V_{i}$ is the starting voltage [42]. The charge time $t$ in the soil can be associated with the soil VWC.

Fig.2. System architecture of the green automated wireless system (GAWS)

\section{B. Wireless control center (WCC)}

The intelligent WCC consists of the three main parts: water distribution, communication and control. It is also equipped with a photovoltaic unit for energy generation from the sun. Basically, the WCC is responsible for managing and scheduling irrigation activities in the GAWS. It relies on information transmitted by the WSUs for irrigation decision making and control. In effect, it provides the autonomy in the GAWS by performing certain functions that hitherto will be performed by a human. The WCC is linked to every part of the GAWS. It is connected to the solar-powered groundwater pumps via pipes and radio signals for the collection of groundwater and for communication purposes respectively. The WCC serves as the interface between the farm and the external irrigation system and is also responsible for the distribution of water to various segments of a farm as captured in Fig. 3. When a WSU detects water shortfall in the soil in a given farm section it informs the WCC about this. The information also contains the type of crop and location of the farm segment. With this information, the WCC can know where to irrigate and how much to irrigate. The WCC opens the control valve at that place via the WSN. Next, the WCC triggers one or more solarpowered groundwater pumps equipped with radio receivers to extract groundwater to carry out irrigation. If there is enough water from the pumps then irrigation proceeds in the area where water deficiency had been detected. Otherwise, the WCC falls back on water from the external irrigation source to carry out irrigation. It is possible that two or more WSUs on the same farm segment may signal the WCC about water shortfall consecutively within a short period. This might lead to over-irrigation of a farm area. To overcome this bottleneck, the WCC sets a minimum period between successive irrigations on a given farm segment. For instance, the minimum period between two irrigations on a given farm segment can be set to 1 day. However, when the signals are sent repeatedly with a short period from different WSUs on the same farm segment, it could be an indication of genuine water deficiency. In that case, the WCC overlooks the minimum timeframe before irrigation to prevent under-irrigation as indicated in Fig. 4. During irrigation, if a WSU from another farm segment detects and transmits a message on water shortfall to WCC, irrigation is scheduled on the next available time for that farm segment on a first-come-first-serve basis.

\section{IRRIGATION WATER ANALYSIS}

For the purpose of analysis, we consider a case of mixed cropping involving four crops, namely maize, millet, sorghum and soybean. Each crop is cultivated on a demarcated section of a farm. It is assumed that WSUs are placed in each farm zone corresponding to each of these crops. The WSUs are able detect shortfall in the amount of water which is needed to meet crop water requirements. Supposing that the mean monthly water requirements for maize, millet, sorghum and soybean is 126, 129, 114 and $99 \mathrm{~mm}$ respectively, then average water requirement is $117 \mathrm{~mm}$. Farms located in the tropical regions with rainy and sunny seasons are to be considered. In these regions, the rainy season starts from May, and ends in October, and the dry season lasts from 
November till April. Table 1 gives the mean rainfall in each month of the year in the region. The crop coefficient $K_{C}$ is taken to be $1.2,1,1.1$ and 1.15 for maize, millet, sorghum and soybean respectively. Based on a reference mean monthly crop evapotranspiration $E T_{o}$ of $114 \mathrm{~mm}$, the mean monthly evapotranspiration for maize, millet, sorghum and soybean is estimated to be 136, 114, 123 and $131 \mathrm{~mm}$ respectively. With these, the mean irrigation water requirements for each crop in each month are calculated as shown in Table 1. The solar groundwater pumps employed on the farm are fancied to deliver a mean monthly irrigation water of $100 \mathrm{~mm}$ to crops.

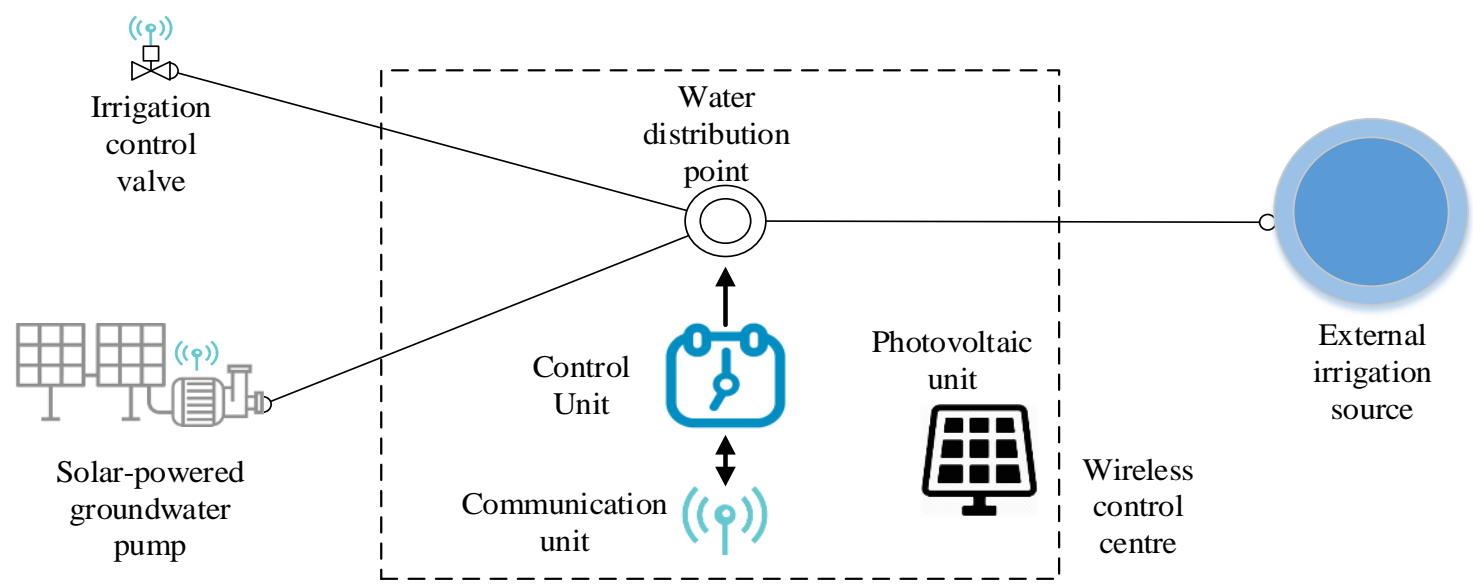

Fig.3. Components of the wireless control centre (WCC)

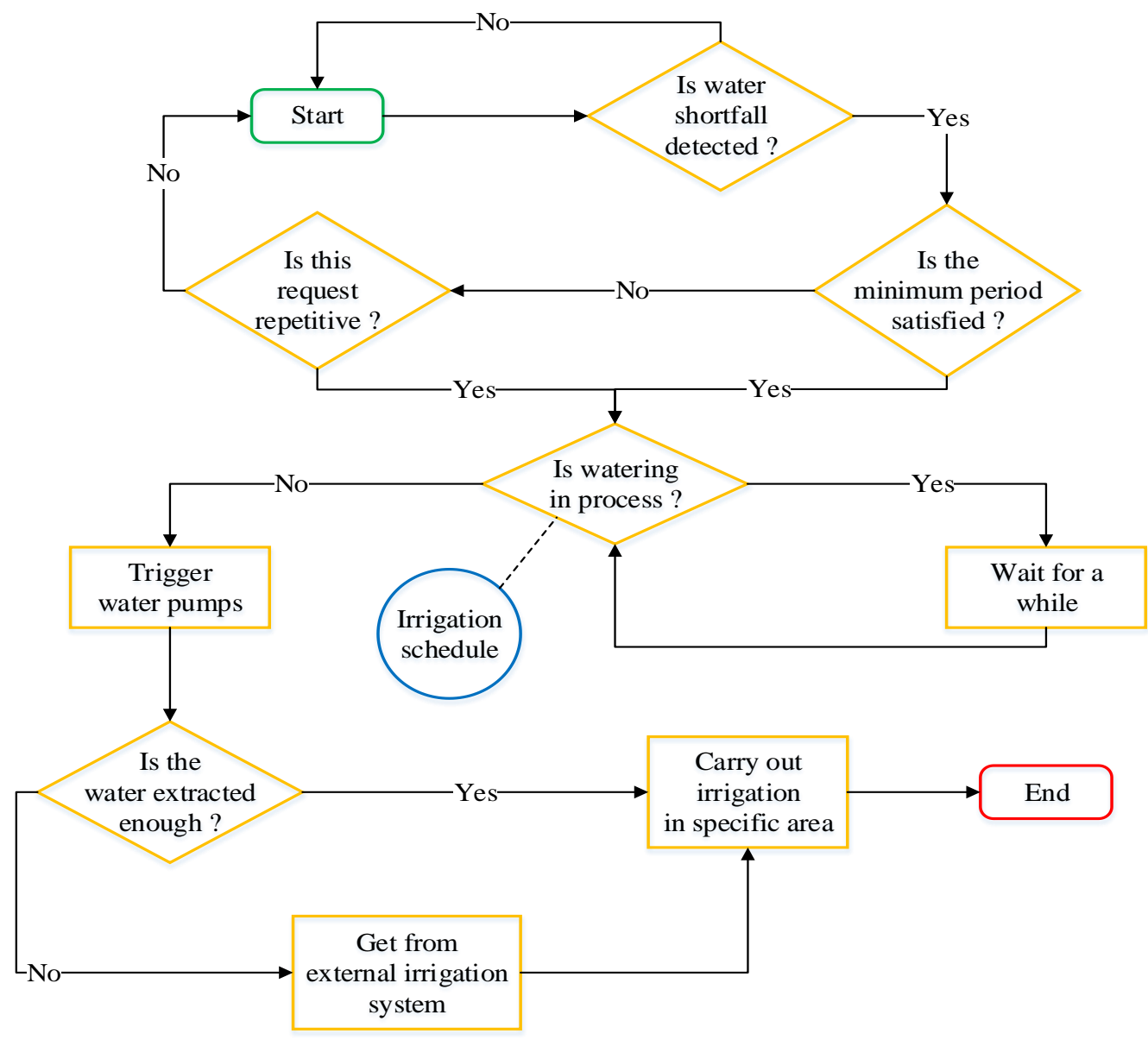

Fig.4. Flow chart of WCC's irrigation control mechanism

In this section, we present results obtained by simulating the irrigation water requirements of the GAWS system on the farm for each month of the year using MATLAB software. The GAWS irrigation system, employing WSUs in all the sections on the farm, is evaluated against four other variant systems and a heuristic irrigation method. In the variant systems, WSUs are placed in only one segment of a farm such that 
irrigation is carried out across the entire farm whenever the WSUs detect a shortfall in soil water required for the normal growth of the crops in that one segment. On the contrary, the GAWS employs WSU in all sections of a farm and irrigates a specific section of a farm upon the detection of shortfall in soil water. The heuristic irrigation

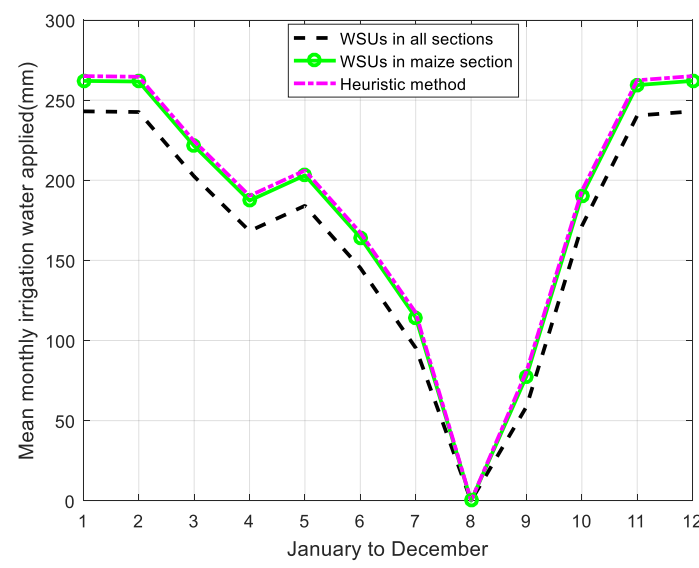

(a)

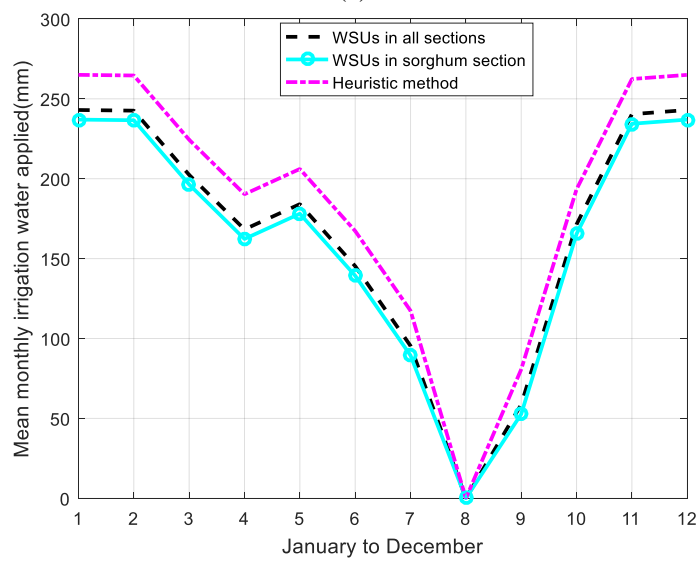

(c) method involves the application of irrigation water in the entire farm by computing IWR based on the highest crop water requirement (i.e. $129 \mathrm{~mm}$ ), the highest crop evapotranspiration (i.e. $136 \mathrm{~mm}$ ) and mean monthly precipitation levels. When water shortfall is detected in any segment of the farm, the computed IWR is applied.

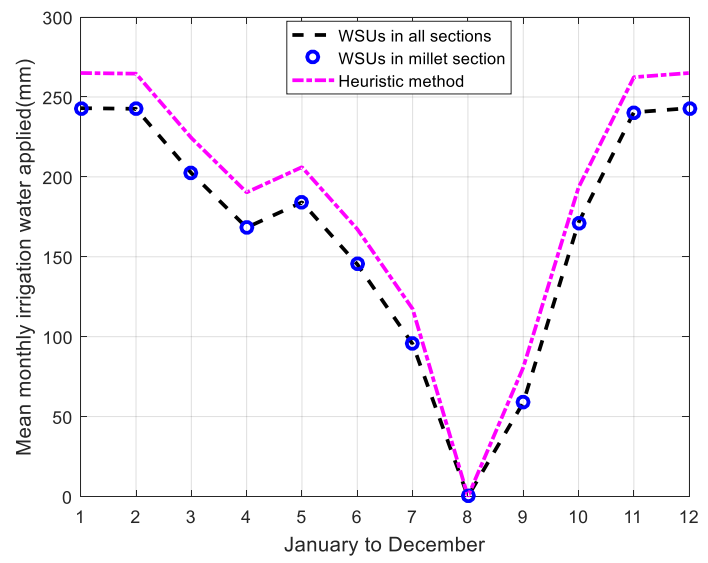

(b)

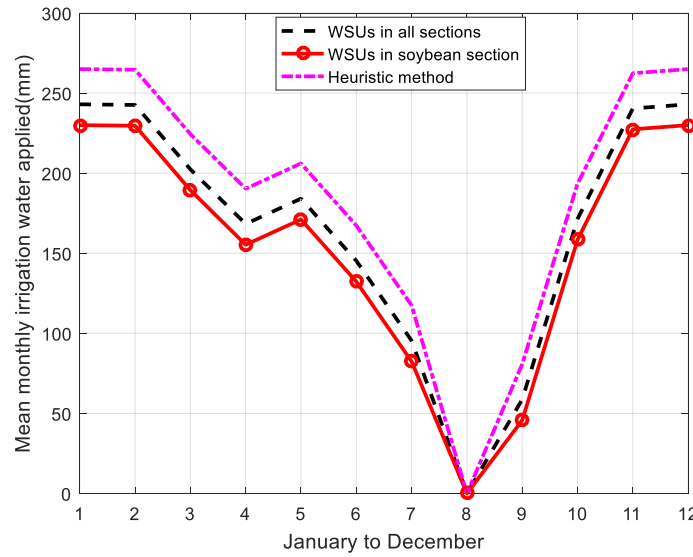

(d)

Fig.5. Mean monthly irrigation water applied in each month using WSUs in all sections, the heuristic method and (a) WSUs in maize section only (b) WSUs

Table 1. Irrigation water requirements for the various crops across the year

\begin{tabular}{c|c|c|c|c|c}
\hline \multirow{2}{*}{ Month } & \multirow{2}{*}{ Mean Precipitation/mm } & \multicolumn{4}{|c}{ Mean Irrigation Water Requirement/mm } \\
\cline { 2 - 5 } & & Maize & Millet & Sorghum & Soybean \\
\hline January & 0 & -262 & -243 & -237 & -230 \\
February & 0.4 & -261.6 & -242.6 & -236.6 & -229.6 \\
March & 40.6 & -221.4 & -202.4 & -196.4 & -189.4 \\
April & 74.7 & -187.3 & -168.3 & -162.3 & -155.3 \\
May & 58.9 & -203.1 & -184.1 & -178.1 & -171.1 \\
June & 97.7 & -164.3 & -145.3 & -139.3 & -132.3 \\
July & 147.6 & -114.4 & -95.4 & -89.4 & -82.4 \\
August & 351.8 & 89.8 & 108.8 & 114.8 & 121.8 \\
September & 184.3 & -77.7 & -58.7 & -52.7 & -45.7 \\
October & 71.6 & -190.4 & -171.4 & -165.4 & -158.4 \\
November & 2.6 & -259.4 & -240.4 & -234.4 & -227.4 \\
December & 0 & -262 & -243 & -237 & -230 \\
\hline
\end{tabular}




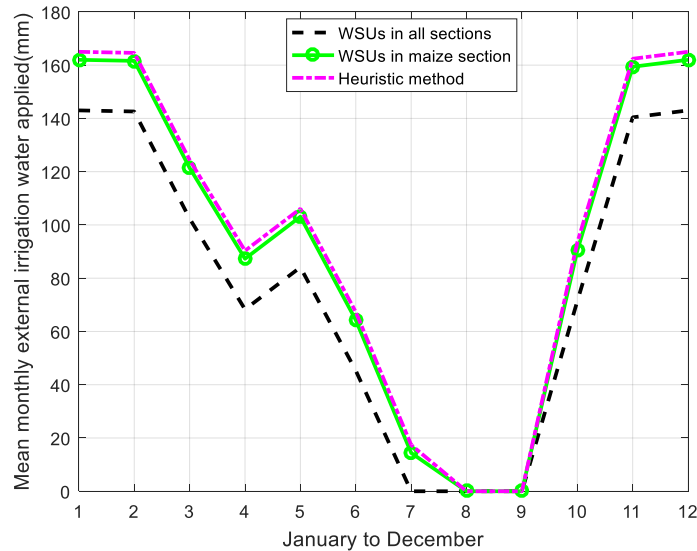

(a)

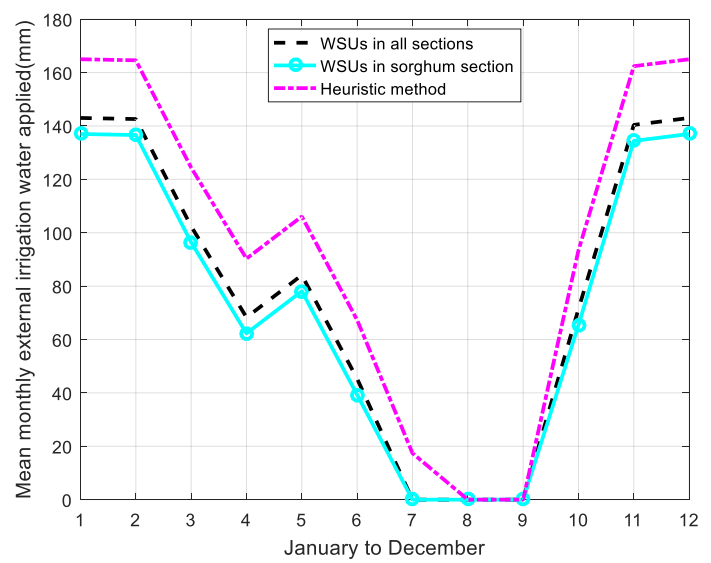

(c)

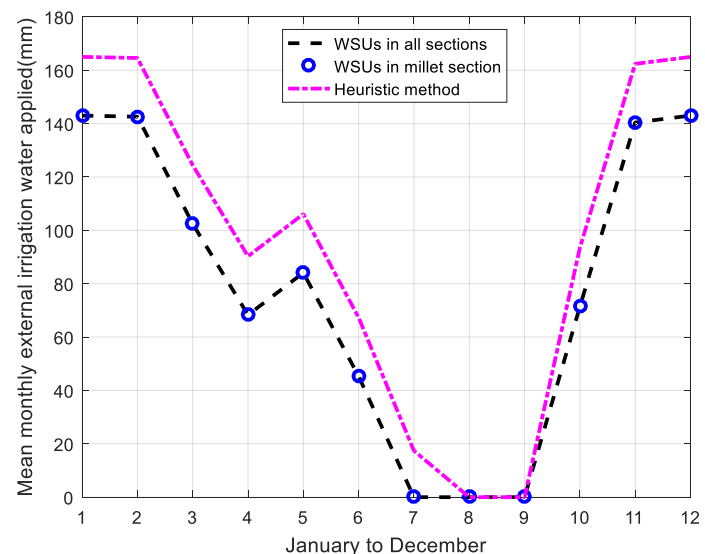

(b)

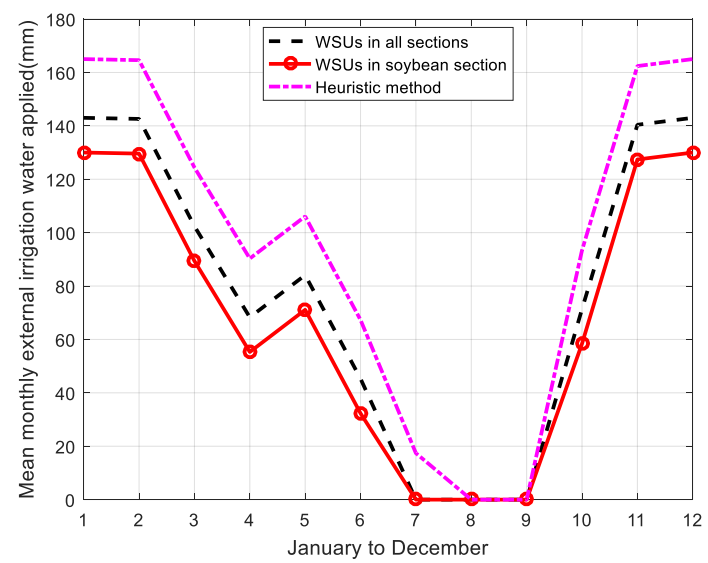

(d)

Fig.6. Mean monthly external irrigation water applied for each month using WSUs in all sections, the heuristic method and (a) WSUs in maize section only (b) WSUs in millet section only (c) WSUs in sorghum section only (d) WSUs in soybean section only

Fig. 5 shows the mean monthly irrigation water applied throughout the year using GAWS, other variant systems and the heuristic irrigation method. We observed, in all the scenarios, that the mean monthly irrigation water applied decreases from January to August. This reduction is attributable to a general increase in precipitation levels as the weather shifts from the dry season to the rainy season. Contrarily, the mean monthly irrigation water applied increases as we move from August towards December, indicating a reversal back to the dry season. As shown in Fig. 5, the heuristic method leads to overirrigation of farmlands since the irrigation is carried out according to a very high IWR. Results of the variant system in Fig. 5(a), which uses WSUs in only the maize section of the farm, show that this system results in overirrigation of the farmland because it executes irrigation according to the water requirements of the maize crop which is higher than those of the other crops in every month. Meanwhile, Fig. 5(b) reveals that the variant system in which WSUs are placed in only millet section produces the same results as GAWS, indicating that the average IWR of all the crops is equal to the IWR of millet. The mean monthly irrigation water applied using a variant system in which WSUs are placed in only the sorghum or soybean section results in under-irrigation as evidenced in Fig. 5(c) and Fig. 5(d). These variant systems are influenced by the IWR of a certain crop and so may result in deficit or excess irrigation. Thus, in comparison to the variant systems, the GAWS achieves an optimal application of irrigation water on farmlands.

We ascertained the mean monthly external irrigation water applied over the year by using GAWS, other variant systems and the heuristic method. The results are depicted in Fig. 6. All the scenarios point to the fact that the mean monthly external irrigation water applied decreases from January to August. Obviously, this is a result of the general increase in precipitation levels as the weather shifts from the dry season to the rainy season. However, as the weather reverts back to the dry season, mean monthly external irrigation water applied increases steadily from September to December. In Fig. 6, the heuristic irrigation method is seen to procure the highest amount of water from the external irrigation source by setting a very high IWR beyond what the solar-powered pumps can supply which will affect supply to other farms. Following the heuristic method, the variant system which uses WSU in only the maize section of the farm gets a higher amount of water from the external irrigation source that GAWS does as revealed in Fig. 6(a). As for the variant system which employs WSU in only the millet section, the amount of water it obtains from the external irrigation source is the same as that of GAWS as evidenced in Fig. 6(b). The mean monthly external irrigation water applied using the variant systems in which WSUs are placed in only the sorghum or soybean sections is lower than that of GAWS, as indicated in 
Fig. 6(c) and Fig. 6(d). This is simply due to their underirrigation of farmlands. Thus, in comparison to the rest, GAWS optimally exploits water from the groundwater or the external source based on specific crop needs.

\section{CONCLUSION}

This paper has proposed a new irrigation system: green automated wireless system (GAWS). The GAWS, to be powered exclusively by solar energy, is designed to manage scarce irrigation water extracted from the ground or procured from an external irrigation source. We have presented the various elements that will enable the proposed GAWS to operate effectively. In particular, we have described in detail the workings of the wireless sensor units (WSUs) and wireless control centre (WCC). Moreover, the irrigation control mechanism for achieving efficient and optimal irrigation has been expansiated. Irrigation water requirements of selected crops namely maize, millet, sorghum and soybean for each month of the year was derived and simulation was done to evaluate the optimality of irrigation water requirements (IWR) of GAWS. Results analysis of the IWR of GAWS and five other irrigation methods, suggest that our proposed green irrigation system will achieve efficient application of irrigation water on farmlands and optimal exploitation of water from external sources based on specific crop needs. Thus, it would enhance crop yields not only for a farm on which it is deployed but also other farm that depends on the external irrigation source. The system could be further improved to prioritize irrigation for certain crops with high water requirements while optimizing water usage.

\section{REFERENCES}

[1] W. A. Jury and H. J. Vaux Jr, "The emerging global water crisis: managing scarcity and conflict between water users," Advances in agronomy, vol. 95, pp. 1-76, 2007.

[2] UNESCO, "The 3rd United Nations World Water Development Report: Water in a Changing World (WWDR-3)," UNESCO, Paris, France2009.

[3] E. Vories, R. Hogan, P. Tacker, R. Glover, and S. Lancaster, "Estimating the Cost of Delaying Irrigation for Midsouth Cotton on Clay Soil," Transactions, vol. 50, pp. 929-937, 2007.

[4] R. Delirhasannia, A. Sadraddini, A. Nazemi, D. Farsadizadeh, and E. Playán, "Dynamic model for water application using centre pivot irrigation," Biosystems engineering, vol. 105, pp. 476-485, Apr 2010.

[5] K. Anand, C. Jayakumar, M. Muthu, and S. Amirneni, "Automatic drip irrigation system using fuzzy logic and mobile technology," in 2015 IEEE Technological Innovation in ICT for Agriculture and Rural Development (TIAR), 2015, pp. 54-58.

[6] J. Schneekloth, T. Bauder, and N. Hansen, "Limited irrigation management: principles and practices," Crop series. Irrigation; no. 4.720, 2009.

[7] N. Xu, "A survey of sensor network applications," IEEE communications magazine, vol. 40, pp. 102-114, 2002.

[8] S. J. Ramson and D. J. Moni, "Applications of wireless sensor networks-A survey," in 2017 International Conference on Innovations in Electrical, Electronics, Instrumentation and Media Technology (ICEEIMT), 2017, pp. 325-329.

[9] M. Hempstead, M. J. Lyons, D. Brooks, and G.-Y. Wei, "Survey of hardware systems for wireless sensor networks," Journal of Low Power Electronics, vol. 4, pp. 11-20, 2008.

[10] D. P. Van Vuuren, E. Stehfest, D. E. Gernaat, J. C. Doelman, M. Van den Berg, M. Harmsen, et al., "Energy, land-use and greenhouse gas emissions trajectories under a green growth paradigm," Global Environmental Change, vol. 42, pp. 237-250, 2017.

[11] V. Abreu and L. Pereira, "Sprinkler irrigation systems design using ISAMim. ASABE Paper No. 022254," Am. Soc. Agric. Biol. Engr., St. Joseph, MI, 2002.

[12] H. Chapman and G. F. Liebig Jr, "Adaptation and use of automatically operated sand-culture equipment," J. Agr. Res, vol. 56, pp. 73-80, 1938.

[13] G. J. Bouyoucos, "A New Electric Automatic Irrigation System 1," Agronomy Journal, vol. 44, pp. 448-451, 1952.

[14] T. Boutraa, A. Akhkha, A. Alshuaibi, and R. Atta, "Evaluation of the effectiveness of an automated irrigation system using wheat crops," Agriculture and Biology Journal of North America, vol. 2, pp. 80-88, 2011.

[15] F. Miranda, R. Yoder, J. Wilkerson, and L. Odhiambo, "An autonomous controller for site-specific management of fixed irrigation systems," Computers and Electronics in Agriculture, vol. 48, pp. 183-197, 2005.

[16] R. T. Peters and S. R. Evett, "Automation of a center pivot using the temperature-time-threshold method of irrigation scheduling," Journal of irrigation and drainage engineering, vol. 134, pp. 286-291, May-Jun 2008.

[17] S. O'Shaughnessy and S. R. Evett, "Canopy temperature based system effectively schedules and controls center pivot irrigation of cotton," Agricultural Water Management, vol. 97, pp. 1310-1316, Sep 2010.

[18] H. L. Zhu and X. Li, "Study of automatic control system for irrigation," in Advanced Materials Research, 2011, pp. 1463-1467.

[19] S. Chaudhry and S. Garg, "Smart Irrigation Techniques for Water Resource Management," in Smart Farming Technologies for Sustainable Agricultural Development, ed: IGI Global, 2019, pp. 196-219.

[20] Y. Zhou, X. Yang, L. Wang, and Y. Ying, "A Wireless Design of Low-Cost Irrigation System Using ZigBee Technology," pp. 572-575, 2009.

[21] H. Gu-Zhah and H. Ching-Lu, "Application of Integrated Control Strategy and Bluetooth for Irrigating Romaine Lettuce in Greenhouse," 2016.

[22] Y. Sun, L. Li, P. S. Lammers, Q. Zeng, J. Lin, and H. Schumann, "A solar-powered wireless cell for dynamically monitoring soil water content," Computers and Electronics in Agriculture, vol. 69, pp. 19-23, Nov 2009.

[23] S. Khriji, D. El Houssaini, M. W. Jmal, C. Viehweger, M. Abid, and O. Kanoun, "Precision irrigation based on wireless sensor network," IET Science, Measurement \& Technology, vol. 8, pp. 98-106, May 2014.

[24] N. Zhang, M. Wang, and N. Wang, "Precision agriculture-a worldwide overview," Computers and electronics in agriculture, vol. 36, pp. 113-132, 2002.

[25] A. Srinivasan, Handbook of precision agriculture: principles and applications: CRC press, 2006.

[26] N. Wang, N. Zhang, and M. Wang, "Wireless sensors in agriculture and food industry-Recent development and future perspective," Computers and electronics in agriculture, vol. 50, pp. 1-14, 2006.

[27] L. Ruiz-Garcia, L. Lunadei, P. Barreiro, and I. Robla, "A review of wireless sensor technologies and applications in 
agriculture and food industry: state of the art and current trends," sensors, vol. 9, pp. 4728-4750, 2009.

[28] K. Stone, A. Smajstria, and F. Zazueta, "Microcomputer: based data acquisition system for continuous soil water potential measurements," Proceedings-Soil and Crop Science Society of Florida (USA), 1985.

[29] B. Jacobson, P. H. Jones, J. Jones, and J. Paramore, "Realtime greenhouse monitoring and control with an expert system," Computers and electronics in agriculture, vol. 3, pp. 273-285, 1989.

[30] F. Zazueta and A. Smajstrla, "Microcomputer-based control of irrigation systems," Applied Engineering in Agriculture, vol. 8, pp. 593-596, 1992.

[31] M. Meron, R. Assaf, B. Bravdo, R. Wallach, R. Hallel, A. Levin, et al., "Soil sensor actuated microirrigation of apples," in Proceedings of the 5th International Microirrigation Congress, ASABE, 1995, pp. 486-491.

[32] R. Testezlaf, F. Zazueta, and T. Yeager, "A real-time irrigation control system for greenhouses," Applied Engineering in Agriculture, vol. 13, pp. 329-332, 1997.

[33] S. Angal, "Raspberry Pi and Arduino based automated irrigation system," International Journal of Science and Research (IJSR), vol. 5, pp. 1145-1148, 2016.

[34] P. H. Tarange, R. G. Mevekari, and P. A. Shinde, "Web based automatic irrigation system using wireless sensor network and embedded Linux board," in 2015 International Conference on Circuits, Power and Computing Technologies [ICCPCT-2015], 2015, pp. 1-5.

[35] B. M. McGill, S. K. Hamilton, N. Millar, and G. P. Robertson, "The greenhouse gas cost of agricultural intensification with groundwater irrigation in a Midwest US row cropping system," Global change biology, vol. 24 pp. 5948-5960, Dec 2018.

[36] H. A. Kazem, A. H. Al-Waeli, M. T. Chaichan, A. S. AlMamari, and A. H. Al-Kabi, "Design, measurement and evaluation of photovoltaic pumping system for rural areas in Oman," Environment, Development and Sustainability, vol. 19, pp. 1041-1053, Jun 2017.

[37] M. A. Hossain, M. S. Hassan, M. A. Mottalib, and S. Ahmmed, "Technical and economic feasibility of solar pump irrigations for eco-friendly environment," Procedia Engineering, vol. 105, pp. 670-678, 2015.

[38] A. Closas and E. Rap, "Solar-based groundwater pumping for irrigation: Sustainability, policies, and limitations," Energy Policy, vol. 104, pp. 33-37, May 2017.

[39] C. S. Leggett and B. D. Beattie, "Wireless Irrigation and Trespasser Deterrent Control System (WITDCS)," ed: Google Patents, 2008.

[40] R. W. Coates, M. J. Delwiche, A. Broad, and M. Holler, "Wireless sensor network with irrigation valve control," Computers and electronics in agriculture, vol. 96, pp. 1322, Aug 2013.

[41] J. Gutiérrez, J. F. Villa-Medina, A. Nieto-Garibay, and M. Á. Porta-Gándara, "Automated irrigation system using a wireless sensor network and GPRS module," IEEE transactions on instrumentation and measurement, vol. 63 , pp. 166-176, 2013.

[42] F. Kizito, C. Campbell, G. Campbell, D. Cobos, B. Teare, B. Carter, et al., "Frequency, electrical conductivity and temperature analysis of a low-cost capacitance soil moisture sensor," Journal of Hydrology, vol. 352, pp. 367378, May 152008.

[43] S. Lecina and E. Playán, "Model for the simulation of water flows in irrigation districts. I: Description," Journal of irrigation and drainage engineering, vol. 132, pp. 310321, 2006.

[44] E. Farg, S. Arafat, M. A. El-Wahed, and A. El-Gindy,
"Estimation of evapotranspiration ETc and crop coefficient $\mathrm{Kc}$ of wheat, in south Nile Delta of Egypt using integrated FAO-56 approach and remote sensing data," The Egyptian Journal of Remote Sensing and Space Science, vol. 15, pp. 83-89, 2012.

[45] Y. Kang, S. Khan, and X. Ma, "Climate change impacts on crop yield, crop water productivity and food securityA review," Progress in natural Science, vol. 19, pp. 16651674, 2009.

\section{Authors' Profiles}

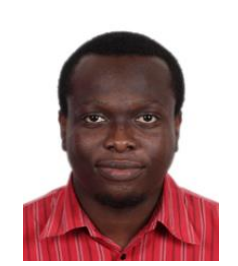

Andrews Allotei Okine received his B.Sc. degree in Telecommunication Engineering from the Kwame Nkrumah University of Science and Technology, Ghana, in June 2014 and the MS degree in Communication and Information Systems from Jiangsu University, China, in June 2019. He was a recipient of the award for the outstanding graduate student of Jiangsu University, in June 2019. Currently, he is a graduate researcher at the Chongqing University of Posts and Telecommunications. Andrews is a graduate student member of the IEEE and his research interests include wireless communication, Internet of things (IoT), precision agriculture, agro-informatics, and applied machine learning.

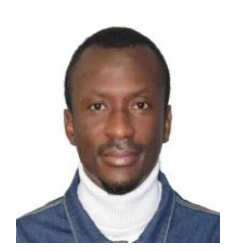

Michael Osei Appiah received his B.Sc. degree in Agricultural Science (Animal Science Major) from the Kwame Nkrumah University of Science and Technology, Ghana, in June 2013.

Since September 2017, he has been with the College of Animal Science and Technology of Jilin Agricultural University as a master's research student. Michael is a member of the Animal Science Team and also part of the Organic Farmers Association of Ghana. His research interests include animal reproduction, genetics and breeding, precision agriculture and agroinformatics.

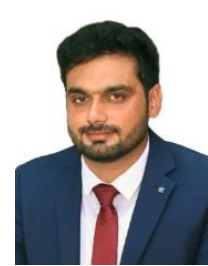

Ibrar Ahmad was born in Khanewal, Pakistan in 1992. He received his bachelor degree in Agricultural Engineering from Bahauddin Zakariya University, Multan, Pakistan in 2015. His main area of interest was the study of application of renewable energy resources for the development of agriculture sector. After that, he joined Jiangsu University, China in 2016 and received his master degree in Agricultural Mechanization Engineering in 2019. His master thesis explored the design and test of belt drive seedling transmission device for automatic plug transplanting.

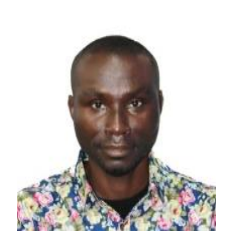

Bismark Asante-Badu received his B.Sc. degree in Agricultural Science (Agric. Mechanization option) from the Kwame Nkrumah University of Science and Technology, Ghana, in June 2013. From July 2013 he worked with several companies to share and improve his knowledge in 
agriculture and mechanization including NGOs, Ministry of Food and Agriculture (engineering department) and Forestry Commission, Ghana. He is currently in the College of Resources and Environmental Science of Jilin Agricultural University, China as a master's degree student. His research interests include plant nutrition, soil science, environmental management, environmental conservation and agricultural mechanization.

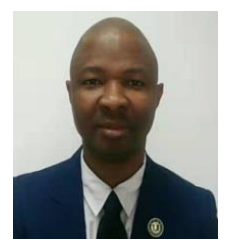

Benjamin Bernard Uzoejinwa is a lecturer at the Department of Agricultural and Bioresources Engineering, University of Nigeria. $\mathrm{He}$ obtained the B.Eng and M.Eng degrees all in Agricultural and Bioresources Engineering from the University of Nigeria in 2008 and 2013 respectively. In June 2019, he received the $\mathrm{PhD}$ degree in Power Engineering and Engineering Thermophysics from Jiangsu University, China. Benjamin is a member of the International Soil Tillage Research Organization (ISTRO). His research interests include power systems and machinery engineering, biosystems engineering, fuel cell systems, bioenergy, waste-to-energy technology, renewable energy and environmental engineering.

How to cite this paper: Andrews A. Okine, Michael O. Appiah, Ibrar Ahmad, Bismark Asante-Badu, Benjamin B. Uzoejinwa, "Design of a Green Automated Wireless System for Optimal Irrigation", International Journal of Computer Network and Information Security(IJCNIS), Vol.12, No.3, pp.22-32, 2020. DOI: $10.5815 /$ ijcnis.2020.03.03 